\title{
Utility of Sonography in the Diagnosis of Bronchopulmonary Sequestration
}

\author{
By Alan E. Schlesinger, Michael A. DiPietro, Mindy B. Statter, and Kevin P. Lally \\ Ann Arbor, Michigan and Houston, Texas
}

\begin{abstract}
- Sonography in six patients with pulmonary sequestration demonstrated findings associated with and indicative of that diagnosis. The most useful feature, which was seen in three cases and is diagnostic of sequestration, is the identification of an anomalous systemic artery arising from the aorta.
\end{abstract}

Copyright $\odot 1994$ by W.B. Saunders Company

INDEX WORDS: Pulmonary sequestration.

$\mathbf{P}$ RENATAL and postnatal sonographic demonstration of bronchopulmonary sequestrations have been reported sporadically in the radiological literature. ${ }^{1-5}$ The anomalous systemic arterial supply has also been demonstrated sonographically. ${ }^{6-17} \mathrm{We}$ describe six cases that show the spectrum of sonographic findings in bronchopulmonary sequestration. Most importantly, these cases emphasize that sonography can expeditiously confirm the diagnosis of sequestration by demonstrating the anomalous systemic arterial supply, and thereby may obviate the need for further imaging.

\section{CASE REPORTS}

\section{Case 1}

B.M. had a right lung cyst that had been noted sonographically while in utero. After birth the initial chest radiograph showed an apparent consolidation of the right upper lobe. However, there was no evidence of respiratory distress, and oxygen saturation was in the range of $95 \%$ to $100 \%$ on room air. Sonugraply of the mediastinum showed a $2.25-\times 2.50-\mathrm{cm}$ fluid-containing cyst at the interface of lung and mediastinum. A follow-up chest radiograph at 3 months of age showed an enlarging mediastinal mass, and computed tomography (CT) at that time showed a large cystic mass at the junction of the right upper lobe and the mediastinum. During surgery, a cystic extralobar sequestration with systemic arterial supply was found in the mediastinum, and was excised.

\section{Case 2}

M.A. was a white girl in whom in utero sonography (at approximately 28 weeks' gestation) showed an intraabdominal echogenic mass. Sonography on postnatal day 6 demonstrated a solidappearing homogeneously hyperechoic mass in the left suprarenal

From the Sections of Pediatric Radiology and Pediatric Surgery, University of Michigan Hospitals, C.S. Mott Children's Hospital, Ann Arbor, MI, and the Division of Pediatric Surgery, UTHSC Houston, Houston, $T X$.

Date accepted: October 7, 1992.

Address reprint requests to Alan $E$. Schlesinger, $M D$, Mallinckrodt Institute of Radiology, 510 S Kingshighway, St Louis, MO 63110.

Copyright 01994 by W.B. Saunders Company

0022-3468/94/2901-0011\$03.00/0 region. The mass appeared distinct from the kidney and displaced the adrenal gland laterally. A CT scan confirmed the presence of a suprarenal mass on the left. During surgery on postnatal day 11 , a $1.5-\mathrm{cm}$ solid extralobar sequestration was noted within the leaves of the left hemidiaphragm. Blunt and sharp dissection were required to separate it from the muscle of the diaphragm. Several large anomalous arteries supplying the mass were ligated; the largest of these appeared to originate from the aorta. The mass was clearly separate from the left adrenal gland.

\section{Case 3}

C.G. was an infant girl in whom a left lower lobe density was noted incidentally on a chest radiograph at 2 months of age. During sonography, a solid hyperechoic mass was identified in the medial paraspinal portion of the left lower lobe. Furthermore, a large tortuous vessel, with at least half the aortic diameter, was demonstrated coursing from the aorta to the echogenic mass. Duplex Doppler sonography confirmed the arterial nature of the vessel. A contrast-enhanced CT scan confirmed the sonographic findings (Fig 1), and a left lower lobectomy showed an intralobar sequestration.

\section{Case 4}

N.G. was a $3.26-\mathrm{kg}$ full-term boy with an antenatal sonographic diagnosis of left cystic adenomatoid malformation. A chest radiograph at birth showed dextrocardia and a left lower lobe opacity, which had been observed antenatally. Echocardiography showed dextrocardia and normal intracardiac anatomy, and a CT scan demonstrated a mass in the left lung base. During sonography, a large vessel was seen, which arose from the left side of the abdominal aorta, coursed cephalad through the diaphragm, and entered the mass. The vessel had arterial flow by duplex Doppler interrogation. During surgery, intralobar sequestration was found. which required a left lower lobectomy for complete excision.

\section{Case 5}

M.K. was a $3.95-\mathrm{kg}$ full-term boy in whom cyanosis and tachypnea developed on the second day of life. During the physical examination, heart sounds were noted on the right and decreased breath sounds on the left. A chest radiograph showed mediatinal shift to the right and a homogenous opacity occupying the left hemithorax. An echocardiogram showed normal intracardiac anatomy. Sonography showed a large, solid, hyperechoic intrathoracic mass with branching tubular structures within the lesion. These were probably vessels; however, Doppler sonography was not yet in use at the time of presentation. CT showed a mass in the posterior left hemithorax, and displacement of a normal-appearing lung. The patient underwent thoracotomy and resection of an extralobar sequestration.

\section{Case 6}

M.H. was an 18-month-old asymptomatic boy who had a history of a heart murmur. An echocardiogram demonstrated a patent ductus arteriosus, and a subsequent chest radiograph showed a small left retrocardiac density. Sonography showed an anomalous 
vessel branching from the aorta and coursing cephalad into an echogenic mass. Duplex Doppler interogation of this vessel showed arterial blood flow. Magnetic resonance imaging confirmed the sonographic findings (Fig 2). The patient underwent thoracotomy
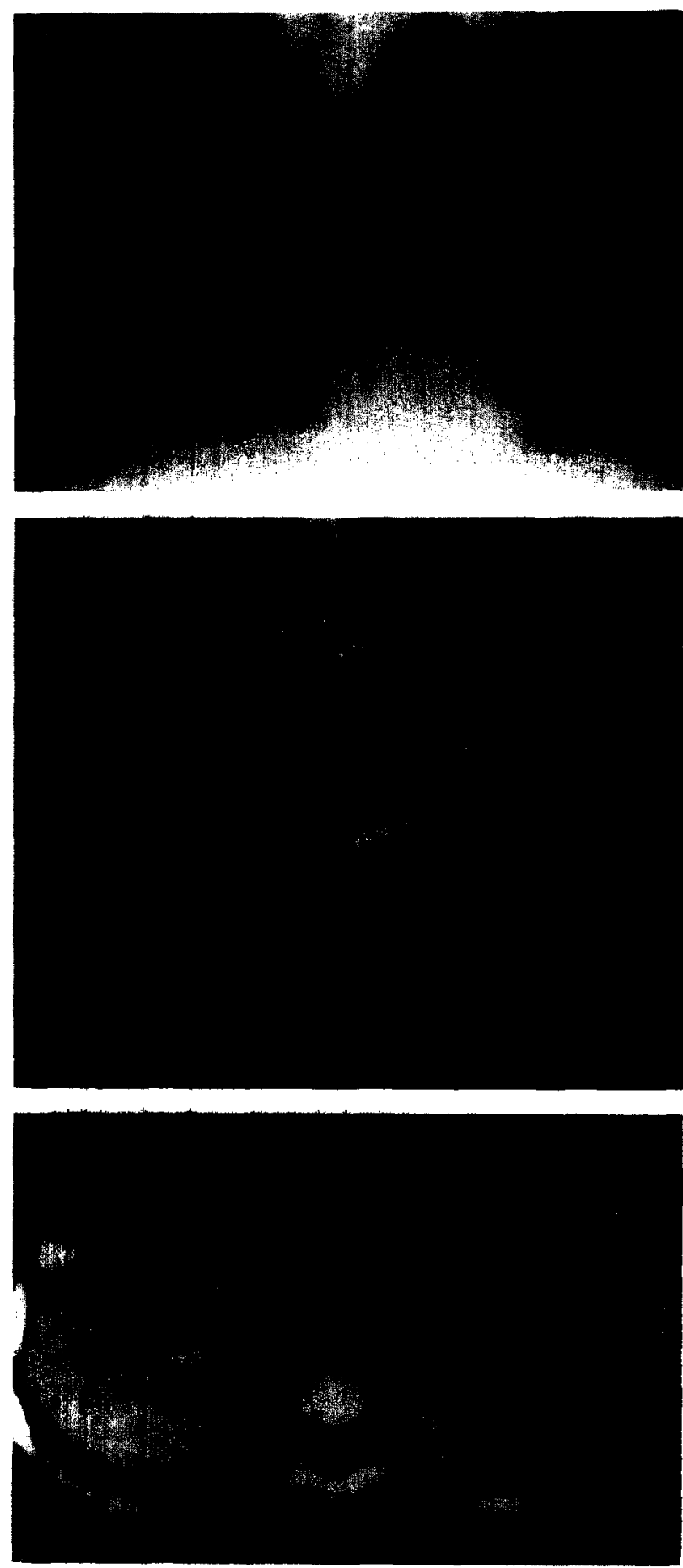

Fig 1. (A) Frantal chest radiograph in a 2-month-old girl shows a left retrocardiac opacity (arrows). (B) Axial sonographic image shows a large, tortuous vessel (asterisk) arising from the aorta (Ao). In other images (not shown) it was noted that the vessel entered the echogenic sequestration (arrows). (C) Axial CT section (through the same level as that in Fig $1 \mathrm{~B}$ ) confirms the presence of the anomalous artery (asterisk) and the sequestration (arrows). with ligation of the patent ductus arteriosus and left lower lobectomy for complete removal of an intralobar pulmonary sequestration.

\section{DISCUSSION}

Bronchopulmonary sequestration is a congenital abnormality within the spectrum of bronchopulmonary foregut malformations ${ }^{18-21}$ in which a sequestered portion of lung parenchyma, without normal bronchial communication, has an anomalous systemic
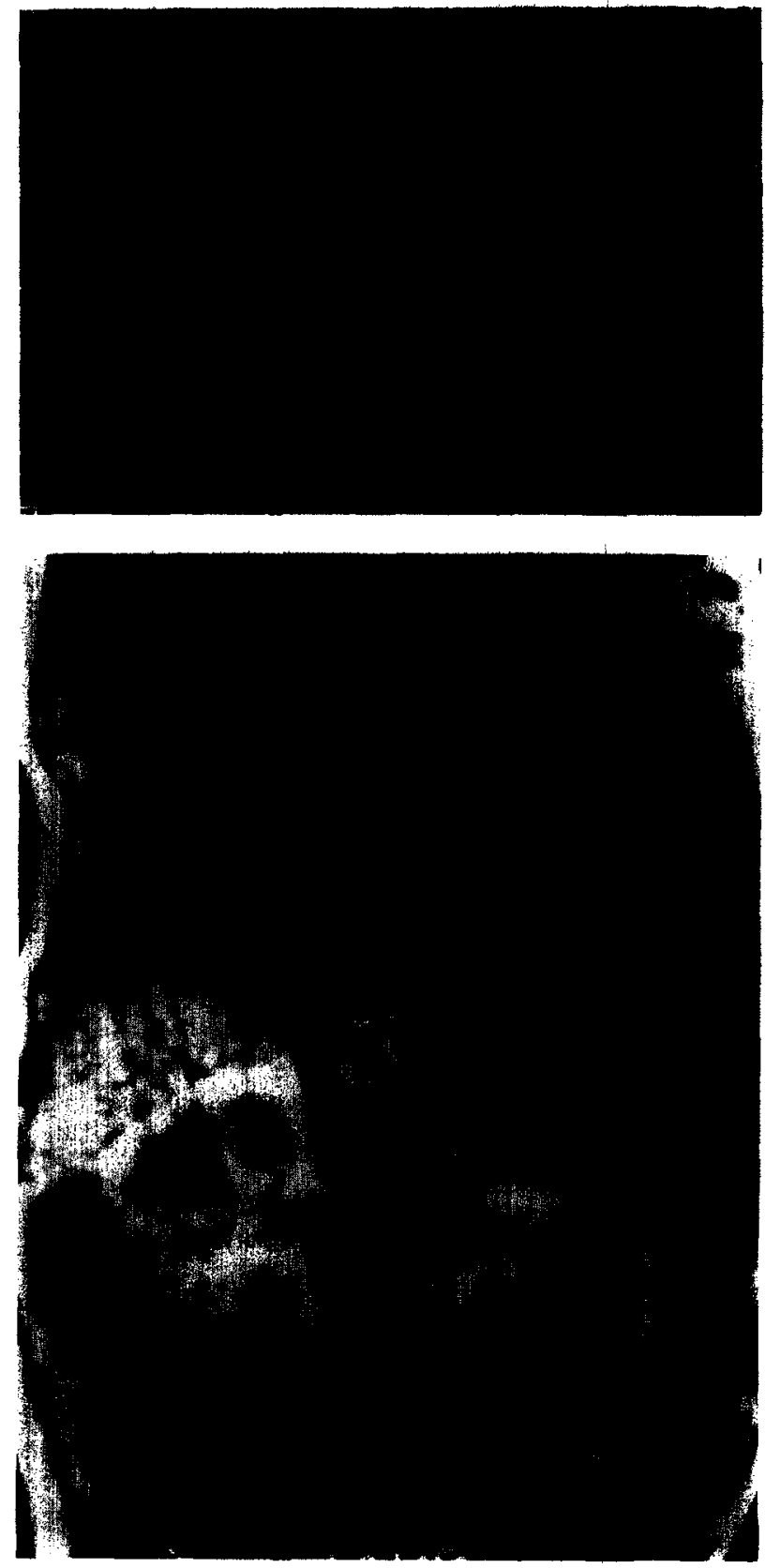

Fig 2. (A) Axial sonographic image at the level of the sequestration (arrows) shows an anomalous artery (arrowheads) arising from the aorta $(A \circ)$. (B) Coronal magnetic resonance image ( $T_{1}$-weighted) shows the anomalous artery (arrowheads) arising from the aorta (Ao), 
arterial supply. This anomalous artery is the hallmark of pulmonary sequestration. ${ }^{19}$ Previous sonography studies of sequestrations showed solid $2-6,8,9,11-17$ or cystic ${ }^{1,7,10}$ masses. Typically the sequestrations were in the posterior basal segments of the lung, although unusual locations have been reported, such as beneath the diaphragm. ${ }^{1}$ Anomalous systemic arteries have been visualized sonographically. ${ }^{6-17}$ Duplex Doppler sonography can confirm the presence of an anomalous vessel and its arterial flow. 6,9

Our cases demonstrate the spectrum of sonographic findings seen in sequestrations. Sonography can determine the cystic or solid nature of the mass, localize the mass, and, most importantly, identify the anomalous systemic arterial supply. The sonographic examination in case 1 demonstrates a purely cystic lesion. In the other cases, the sequestrations appeared hyperechoic and solid on sonography. Cases 1 and 2 represent sequestrations in unusual locations: adjacent to the right upper lobe (case 1) and within the leaves of the hemidiaphragm (case 2). Sonography localized the masses in these cases and identified the relationship of the mass to adjacent structures. Cases 3, 4, and 6 show that duplex Doppler sonography can identify the anomalous systemic arterial flow to the sequestration. The anomalous blood supply to a congenital lung malformation is the hallmark of the diagnosis of sequestration. Therefore, identification of these anomalous systemic arteries is the crux of the sonographic diagnosis of bronchopulmonary seques- tration. Anomalous systemic arterial supply was suspected in case 5 , as evidenced by tubular sonolucent structures cxtending into the sequestration. This case predated Doppler sonography, and confirmation of arterial flow was not possible. Although anomalous vessels were not identified in cases 1 and 2 , the studies were performed early in our investigation of sonography of bronchopulmonary sequestrations. At that time we were merely attempting to identify the lesions, and were not searching for anomalous blood supply.

In conclusion, pulmonary sequestration demonstrates a spectrum of sonographic findings. The sequestration may have the typical basilar location or an unusual location such as the upper thorax or the abdomen. It may be cystic or solid. The pathognomonic anomalous systemic artery may be demonstrated sonographically, especially when the sequestration is in the lower chest or upper abdomen, where the aorta is readily visible. Therefore, sonography can be a useful screening examination in cases in which bronchopulmonary sequestration is suspected from the chest radiograph. If typical sonographic findings of sequestration are noted (including anomalous arterial blood supply), the diagnosis is confirmed, and additional imaging may not be necessary. Therefore, the ionizing radiation from CT can be avoided, as well as the expense and risk of sedation for magnetic resonance imaging.

\section{REFERENCES}

1. McClelland RR, Kapsner AL, Uecker JH: Pulmonary sequestration associated with a gastric duplication cyst. Radiology 124:1314,1977

2. Mariona F, McAlpin G, Zador I, et al: Sonographic detection of fetal extrathoracic pulmonary sequestration. J Ultrasound Med 5:283-285, 1986

3. Siffring PA, Forrest TS, Hill WC, et al: Prenatal sonographic diagnosis of bronchopulmonary foregut malformation. J Ultrasound Med 8:277-280, 1989

4. Romero R, Chervenak FA, Kotzen J, et al: Antenatal sonographic findings of extralobar pulmonary sequestration. $J$ Ultrasound Med 1:131-132, 1982

5. Maulik D, Robinson L, Daily DK, et al: Prenatal sonographic depiction of intralobar pulmonary sequestration. J Ultrasound Med 6:703-706, 1987

6. Hernanz-Schulman M, Stein SM, Neblett WW, et al: Pulmonary sequestration: Diagnosis with color Doppler sonography and a new theory of associated hydrothorax. Radiology 180:817-821, 1991

7. Thind CR, Pilling DW: Case Report. Pulmonary sequestration: The value of ultrasound. Clin Radiol 36:437-439, 1985

8. Kaude JV, Laurin S: Ultrasonographic demonstration of systemic artery feeding extrapulmonary sequestration. Pediatr Radiol 14:226-227, 1984
9. Newman B: Real-time ultrasound and color-Doppler imaging in pulmonary sequestration. Pediatrics 86:620-623, 1990

10. Gudinchet F, Anderegg A: Echography of pulmonary sequestration. Eur J Radiol 9:93-95, 1989

11. West MS, Donaldson JS, Shkolnik A: Pulmonary scquestration. J Ultrasound Med 8:125-129, 1989

12. Liu P, Daneman A, Stringer DA: Real-time sonography of mediastinal and juxtamediastinal masses in infants and children. Journal De L'Association Canadienne Des Radiologistes 39:198203, 1988

13. Jaffe MH, Bank ER, Silver TM, et al: Pulmonary sequestration: Ultrasonic appearance. J Clin Ultrasound 10:294-296, 1982

14. Thind CR, Pilling DW: Case Report. Pulmonary sequestration: The value of ultrasound. Clin Radiol 36:437-439, 1985

15. Kaude JV, Laurin S: Ultrasonographic demonstration of systemic artery feeding extrapulmonary sequestration. Pediatr Radiol 14:226-227, 1984

16. Morin C, Filiatrault D, Russo P: Pulmonary sequestration with histologic changes of cystic adenomatoid malformation. Pediatr Radiol 19:130-132, 1989

17. Tritrakarn A: Pulmonary sequestration: Ultrasonographic visualization of feeding artery. J Med Assoc Thai 72:465-468, 1989 
18. Scully RE, Mark EJ, McNeely WF, et al: Case records of the Massachusetts General Hospital. N Engl J Med 324:980-986, 1991 19. Kirkpatrick JA, Fellows KE, Griscom NT: Sequestration, adenomatoid malformation, bronchogenic cyst, scimitar syndrome: A spectrum? Int Pediatr 3:294-297, 1988
20. Heithoff KB, Sane SM, Williams HJ, et al: Bronchopulmonary foregut malformations. AJR 126:46-55, 1976

21. Gerle RD. Jaretzki A, Ashley CA, et al: Congenital bronchopulmonary-foregut malformation. $\mathrm{N}$ Engl J Med 278:141.3-1419. 1968 